\title{
Rainfall Changes over Southwestern Australia and Their Relationship to the Southern Annular Mode and ENSO
}

\author{
BHUPENDRA A. RAUT \\ Monash Weather and Climate Group, School of Mathematical Sciences, Monash University, Clayton, Victoria, Australia \\ CHRISTIAN JAKOB AND MichaEL J. REEDER \\ Australian Research Council Centre of Excellence for Climate System Science, School of Mathematical Sciences, Monash University, \\ Clayton, Victoria, Australia
}

(Manuscript received 13 December 2013, in final form 8 April 2014)

\begin{abstract}
Since the 1970s, winter rainfall over coastal southwestern Australia (SWA) has decreased by $10 \%-20 \%$, while summer rainfall has been increased by $40 \%-50 \%$ in the semiarid inland area. In this paper, a K-means algorithm is used to cluster rainfall patterns directly as opposed to the more conventional approach of clustering synoptic conditions (usually the mean sea level pressure) and inferring the associated rainfall. It is shown that the reduction in the coastal rainfall during winter is mainly due to fewer westerly fronts in June and July. The reduction in the frequency of strong fronts in June is responsible for half of the decreased rainfall in June-August (JJA), whereas the reduction in the frequency of weaker fronts in June and July accounts for a third of the total decrease. The increase in rainfall inland in December-February (DJF) is due to an increased frequency of easterly troughs in December and February. These rainfall patterns are linked to the southern annular mode (SAM) index and Southern Oscillation index (SOI). The reduction in coastal rainfall and the increase in rainfall inland are both related to the predominantly positive phase of SAM, especially when the phase of ENSO is neutral.
\end{abstract}

\section{Introduction}

Winter rainfall over coastal southwestern Australia (SWA) has declined by about $10 \%-20 \%$ since the 1970 s (IOCI 2002) and seasonal-scale droughts have increased in intensity and longevity in the region (Gallant et al. 2013). This reduction in rainfall has also reduced the dam flows by more than $50 \%$ in the region (Bates et al. 2008). In contrast, the total rainfall and frequency of extreme rainfall events has increased during the summer over inland SWA (Suppiah and Hennessy 1998; Fierro and Leslie 2013).

A number of studies have sought to explain the mechanisms behind the coastal rainfall variability and declining winter rainfall since the 1970s (see IOCI 2002; Nicholls 2006, and references therein). The earliest of the studies have explored the role of large-scale climate

Corresponding author address: Bhupendra A. Raut, School of Mathematical Sciences, Monash University, Clayton Campus, Melbourne VIC 3800, Australia.

E-mail: bhupendra.raut@monash.edu modes, including but not limited to the El NiñoSouthern Oscillation (ENSO), the southern annular mode (SAM), and the Indian Ocean temperatures, in annual and seasonal rainfall variability (McBride and Nicholls 1983; IOCI 2002; Pezza et al. 2008). Although, the connection between rainfall and ENSO is weak over the coastal region of SWA compared to rest of the Australia (McBride and Nicholls 1983), Allan and Haylock (1993) found a strong relationship between declining rainfall along the SWA coast and long-term mean sea level pressure (MSLP) anomalies. They speculated that the fluctuations in the circulation driving these MSLP anomalies may have been influenced by ENSO. Consistent with their speculation, a weak but significant correlation of June-August (JJA) rainfall with the Southern Oscillation index (SOI) and the dipole mode index (DMI) has been reported by Risbey et al. (2009). Nonetheless, during the period over which SWA rainfall has decreased there has been no significant trend in the SOI and therefore it cannot be linked to the long-term trends in rainfall over the region (Chowdhury and Beecham 2010; Nicholls 2010). 
On the other hand, the reduction in winter rainfall over the coastal region has been found to be associated with the positive phase of the daily SAM index (Hendon et al. 2007), although the correlation of the coastal JJA rainfall with the monthly SAM index was found to be insignificant; a significant positive correlation with the monthly index was found only during SON over the inland region (Risbey et al. 2009). Similarly, Meneghini et al. (2007) found no long-term association between the seasonal SAM index and seasonal rainfall in SWA. However, year-to-year variations in southern Australian rainfall are correlated with the SAM index (Nicholls 2010). Feng et al. (2010) reported that the correlation of rainfall with SAM is insignificant when the year of 1964 is excluded from the time series. Thus, it appears that the effect of SAM on the changing rainfall over SWA is still uncertain. Moreover, the various correlations between climate indices and rainfall in all the above studies are either insignificant or barely exceed 0.35 and consequently cannot explain more than $12 \%$ of the variance in the SWA rainfall.

Some studies have sought to explain the decrease in rainfall through changes in the frequency and the strength of synoptic systems in the region. A strong inverse relationship has been found between coastal SWA rainfall and the MSLP over the region (Allan and Haylock 1993; Ansell et al. 2000; Li et al. 2005), indicating the role of large-scale circulation pattern in controlling the rainfall. In particular, the decline in winter rainfall has been associated with the reduced frequency of front-like low pressure systems over the region (Hope et al. 2006; Alexander et al. 2010) and the increases in both station MSLP over SWA and sea surface temperature (SST) over the southern Indian Ocean (Smith et al. 2000). For example, Risbey et al. (2013) found that the reduction in coastal JJA rainfall during 1985-2009 is mostly associated with the frontal systems. Despite a decrease in the number of low pressure systems, the mean annual frequency of fronts in the region, as deduced from several reanalyses, has increased during 1989-2009 (Berry et al. 2011a). It is likely that these conflicting conclusions can be attributed to the different methods used to identify and classify rain-bearing synoptic systems such as fronts, troughs, and cutoff lows (Hope et al. 2014).

In addition to fronts, cutoff lows frequently affect SWA during winter (Qi et al. 1999). Although, cutoff lows produce approximately one-third of the SWA rainfall during April and October, their contribution to rainfall in June and July is less than that at any other time of the year (Pook et al. 2013). Pook et al. (2012) reported a negative trend in the intensity of the cutoff lows but no significant trend in their frequency. Similarly Risbey et al. (2013) found that the rainfall over inland SWA from cutoff lows has decreased during 1985-2009.
Local changes in the land-cover type are also thought to contribute the reduced rainfall along the coast and the increased rainfall over inland area (Pitman et al. 2004), although the magnitude of their contribution is difficult to quantify. It is also difficult to explain how local changes in the land-cover change the frequency of fronts and troughs as summarized in the cluster analysis of Hope et al. (2006) or change the midlatitude storm tracks and position and strength of the jet stream, as reported by Frederiksen and Frederiksen (2007) and Frederiksen et al. (2011).

Cluster analysis is a method commonly used to classify synoptic and surface conditions (Stone 1989; Hope et al. 2006) or radiosonde profiles (Pope et al. 2009) into distinct weather regimes. From the properties of these weather regimes and their trends, inferences are drawn about the physical processes responsible for the associated rainfall and its trend. This approach works well when synoptic regimes are the main focus of the study and the relationship between the defined weather regimes and rainfall is strong. Clustering by Euclidean distance characterizes both the magnitude and the pattern. In addition, for a normally distributed variable like MSLP, the patterns change smoothly from cluster to cluster and clusters are of comparable size. Experience shows that it takes many more clusters to separate the synoptic patterns associated with heavy rainfall. For seasonal rainfall, changes in a few heavy rain events may lead to large changes in the accumulation.

In contrast to this conventional approach, the work described here takes a simple and more direct approach and clusters the daily rainfall directly. Because of gammalike distribution of rainfall, K-means clustering always produces a large cluster for the light rain and comparatively smaller clusters for the moderate and heavy rainfall events, automatically separating light rain days from the extreme events. Thus, there is an advantage in clustering on rainfall compared with other variables.

The technique is explained in section 2 . The results of the clustering are discussed in section 3 . The composite MSLP and horizontal wind are inferred for each cluster. The trends in each of the rainfall clusters are calculated and the monthly changes in rainfall are attributed to the changes in frequency and intensity of the clusters. The combined effects of SOI and SAM are also studied with the help of the rainfall clusters. The results are summarized and conclusions are drawn in section 4 .

\section{Data and methodology}

\section{a. Data}

Gridded daily rainfall at $0.05^{\circ} \times 0.05^{\circ}$ resolution are taken from the Australian Water Availability Project 

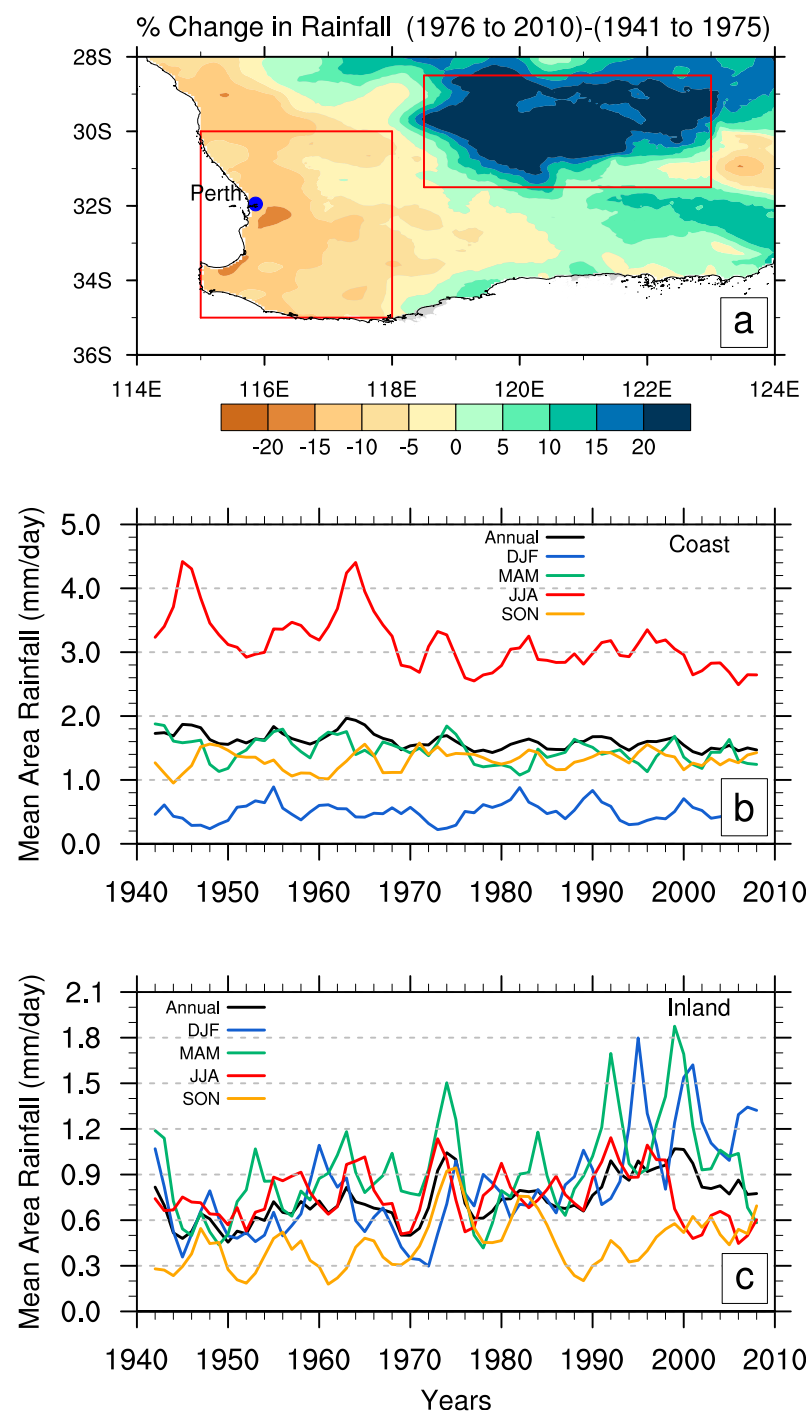

FIG. 1. (a) Percent change in rainfall over southwestern Australia between the two periods 1941-75 and 1976-2010. Time series of annual and seasonal mean area rainfall (land only) over (b) coast and (c) inland regions are as in (a). The seasonal and annual time series are smoothed using 5-point spline.

(AWAP; Raupach et al. 2008; Jones et al. 2009). The base rain gauge data used in the AWAP analysis were collected at 0900 local time, which over Western Australia corresponds to 0100 UTC. The dataset is only available over the land, and the domain used in this study is shown in Fig. 1a. Before clustering, all the days on which the mean area precipitation is less than $0.1 \mathrm{~mm}$ are excluded.

The effect of the resolution of data on the resulting $\mathrm{K}$-means clusters has been investigated. The original $0.05^{\circ}$-resolution data were regridded to $0.1^{\circ}$ and $0.2^{\circ}$ horizontal resolutions. Coarsening the resolution from $0.05^{\circ}$ to $0.1^{\circ}$ had no significant effect on the cluster members; less than $1 \%$ of the days changed cluster. However, for the $0.2^{\circ}$-resolution data, clusters with high rain rates and low populations lost more than $1 \%$ of their members to the lighter rain clusters. Using coarser data is computationally more efficient and hence allows the analysis to be repeated with varying configurations. For this study, we have used $0.1^{\circ} \times 0.1^{\circ}$ resolution data.

Daily sea level pressure (SLP) and 925-hPa wind vectors from the National Centers for Environmental Prediction-National Center for Atmospheric Research (NCEP-NCAR) Reanalysis-1 (Kalnay et al. 1996) are used here. The accumulation period of AWAP rain and the day of the reanalysis data coincides to within $1 \mathrm{~h}$ of each other. Monthly SOI data, based on the pressure differences between Tahiti and Darwin, are obtained from the Australian Bureau of Meteorology (http:// www.bom.gov.au/climate/current/soihtm1.shtml). A monthly SAM index representing the difference in the normalized zonal MSLP between $40^{\circ}$ and $65^{\circ} \mathrm{S}$ (Gong and Wang 1999) for the period 1948-2010 are obtained online (from http://ljp.lasg.ac.cn/dct/page/65572).

\section{b. Cluster analysis}

The K-means clustering algorithm is a method that objectively groups $n$ vectors of any dimensionality, into $k$ clusters using the Euclidean distance as the metric of similarity (Anderberg 1973). Each cluster has an associated centroid, with the members of each cluster lying closer to the centroid than the nonmembers.

Let $x_{i}$ be a vector representing the $i$ th data point and let $\mu_{j}$ be the geometric centroid of the data points in $S_{j}$. Then the K-means algorithm partitions the data into $k$ clusters $S_{j}$ such that $d$ is minimized, where

$$
d=\sum_{j=1}^{k} \sum_{i \in S_{j}}\left|x_{i}-\mu_{j}\right|^{2} .
$$

The days on which the area-averaged rainfall is at least $0.1 \mathrm{~mm}$ are grouped into 5 clusters according to Eq. (1). The number of clusters $k$ was varied between 3 and 9. Although the judgment was subjective, it was found that 5 clusters is a suitable choice for the current study as the most important synoptic and rainfall patterns are captured. Fewer than 5 clusters may not capture all the key patterns while more than 5 clusters only divided the existing clusters into further clusters with similar properties.

\section{c. Trend and breakpoint analysis}

Following Catto et al. (2012b), the change in the total rainfall can be attributed to changes in the intensity and frequency of each cluster. The change in rainfall $\Delta R$ 
between the two periods over a given area can be decomposed as

$\Delta R=\sum_{i=1}^{k} N_{i} \cdot \Delta P_{i}+\sum_{i=1}^{k} P_{i} \cdot \Delta N_{i}+\sum_{i=1}^{k} \Delta N_{i} \cdot \Delta P_{i}$,

where $N_{i}$ and $P_{i}$ are the frequency of occurrence and rainfall intensity of $i$ th regime, respectively and $\Delta N_{i}$ and $\Delta P_{i}$ are the change in the frequency and the intensity for each regime. The first and second terms in Eq. (2) describe the changes in rainfall due to intensity alone and frequency alone, respectively. The third term represents the changes in rainfall due to the combination of changing intensity and frequency. As it is the product of the two changes, it will be small if the changes are much smaller than the values themselves.

As pointed out in section 1 and shown in Fig. 1b, rainfall in JJA along the west coast has declined sharply since 1970s. For this reason, the two consecutive periods chosen for the trend analysis are 1940-74 and 1975-2010. A breakpoint analysis on the annual time series of occurrences of each cluster is used to find abrupt changes in the mean occurrences between these two periods.

\section{Results}

\section{a. Overview of the changing rainfall}

Changes in the rainfall over SWA between the two periods 1941-74 and 1975-2009 and the smoothed time series of the mean area rainfall from 1940 to 2010 are shown in Fig. 1. Most of coastal SWA received $10 \%-$ $15 \%$ less annual rainfall during the later period, with the reduction being up to $20 \%$ south of Perth. In contrast, a large area to the east received around $25 \%$ more annual rainfall compared to the period before 1975 . Figures $1 \mathrm{~b}$ and $1 \mathrm{c}$ are 5-point smoothed time series over the coastal and inland areas, respectively. The time series of the mean coastal area precipitation shows a decrease in JJA during the 1970s and a gradual decline after the 1990s. The change in the mean precipitation over the inland area is more gradual and spread across the seasons, although a few extreme events skew the distribution in this comparatively arid region.

The seasonal rainfall patterns and the rainfall changes between 1940-74 and 1975-2010 are shown as percentages and in millimeters per day in Fig. 2. The highest seasonal mean rainfall $\left(>5 \mathrm{~mm} \mathrm{day}^{-1}\right)$ is in JJA and is confined to a narrow coastal strip approximately $100 \mathrm{~km}$ in width along the southwest of Western Australia. The rain rate decreases eastward to about $1 \mathrm{~mm} \mathrm{day}^{-1}$. The same pattern is followed in SON, although the rain rates along the coast lie in the range of $2-3 \mathrm{~mm} \mathrm{day}^{-1}$. In summer [December-February (DJF)], comparatively more rain falls over the inland area than along the coast, where totals are typically less than $0.5 \mathrm{~mm} \mathrm{day}^{-1}$. Thus, the rainfall in the region shows a distinct geographic distribution and pronounced seasonal cycle. The patterns are also imprinted on the changes in post-1970s period. The reduction in March-May (MAM) and JJA rainfall is mostly confined to the coastal area while the increase to the east is prominent during DJF but nearly absent during JJA.

\section{b. Rainfall patterns}

The five rainfall clusters obtained from the K-means algorithm and their associated MSLP composites and wind vectors are shown in Fig. 3. The monthly occurrences of each cluster type (except dry days) are shown in Fig. 4. Dry days (38\%) are designated as cluster 0 and are associated with a persistent high pressure area over the domain. Cluster 1 is the most frequent (47\%) and is characterized by light rain rates $\left(<0.5 \mathrm{~mm} \mathrm{day}^{-1}\right)$ over most of the region with the moderate rain rates (1$2 \mathrm{~mm}$ day $^{-1}$ ) over the narrow coastal strip to the south and the west. A region of high pressure is located west of the western coast and the winds are predominantly southerly over the domain with westerlies over the Southern Ocean.

Although cluster 1 is the most frequent and occurs throughout the year, it contributes only about $25-30 \%$ to the annual rainfall (see Fig. 4). Clusters $2(9 \%)$ and 3 $(2 \%)$ are associated with heavy coastal rainfall over the southwest, decreasing northeastward. Both clusters are associated with front-like features in their MSLP patterns with predominantly northwesterly flow over SWA. As shown in Fig. 4, the occurrence of clusters 2 and 3 is highly seasonal (with winter maxima). They contribute approximately $70 \%$ of the JJA rainfall and $60 \%$ of the annual rainfall for the coastal area shown in the Fig. 1. Although clusters 1 (47\%), 4 (3.5\%), and 5 $(0.3 \%)$ show light to heavy rainfall over the inland area, clusters 1 and 4 contribute approximately $30 \%$ and $35 \%$ of the annual rainfall over the inland region, respectively. Both clusters 4 and 5 are associated with easterly winds over the domain and a southwardextending easterly trough. Cluster 5 occurs exclusively in mid- and late summer (January-March) and is the least frequent of all the clusters. Although cluster 4 occurs throughout the year, it is more frequent in summer than in winter.

\section{c. Trends in rainfall patterns}

The reduction in total annual rainfall over the coastal region between the two periods is approximately $10 \%$ $(>50 \mathrm{~mm})$, and the increase over the inland area is about 

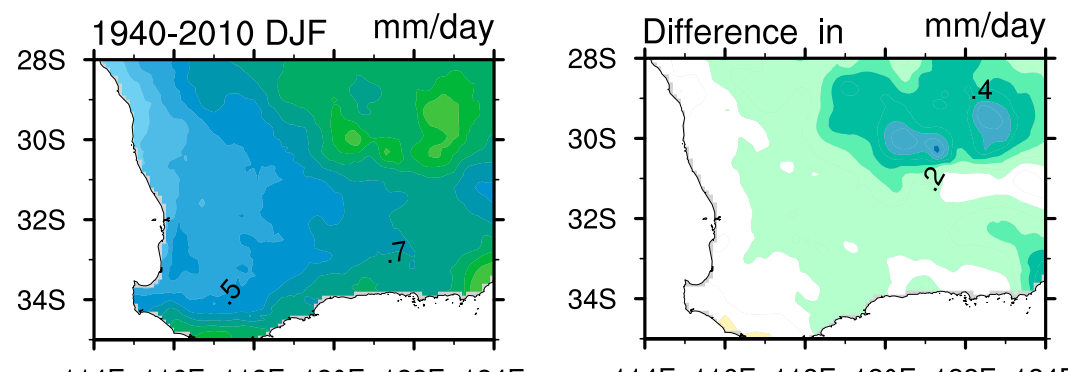

114E 116E 118E 120E 122E 124E

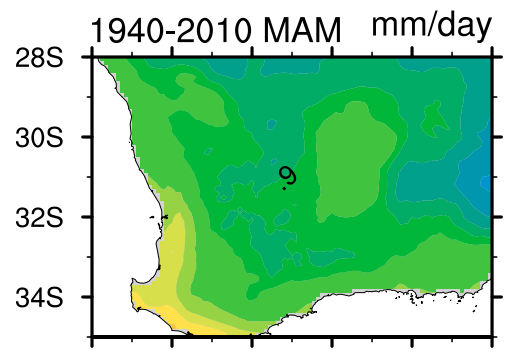

114E 116E 118E 120E 122E 124E

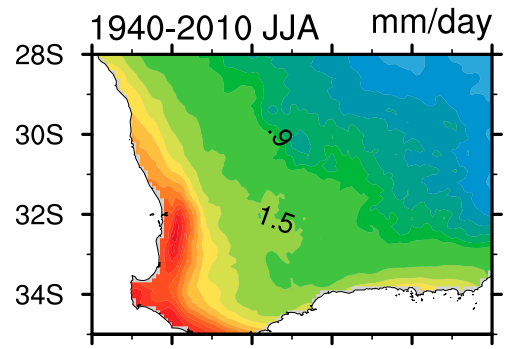

114E 116E 118E 120E 122E 124E

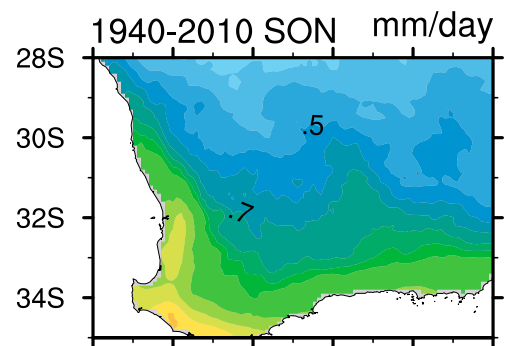

114E 116E 118E 120E 122E 124E

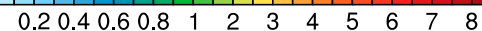

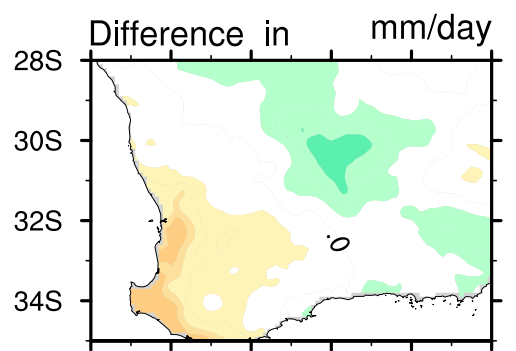

114E 116E 118E 120E 122E 124E

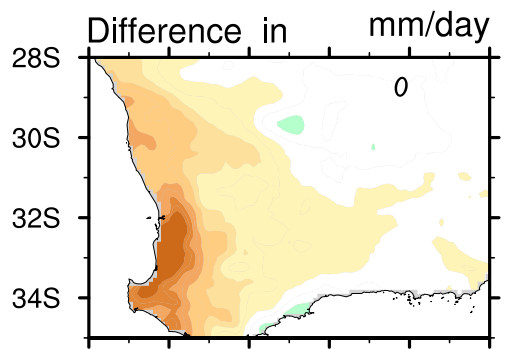

114E 116E 118E 120E 122E 124E

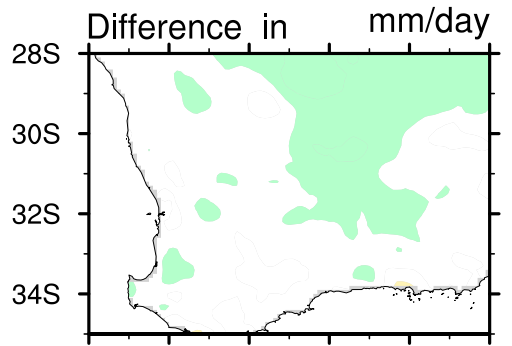

114E 116E 118E 120E 122E 124E

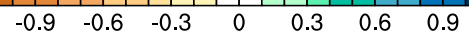

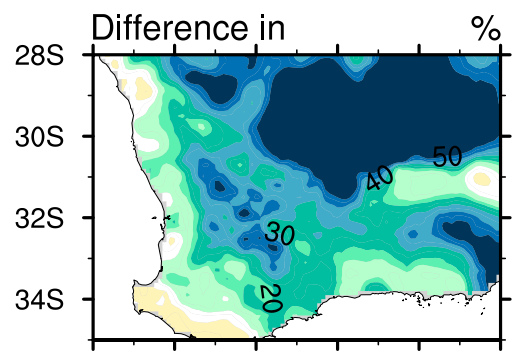

114E 116E 118E 120E 122E 124E

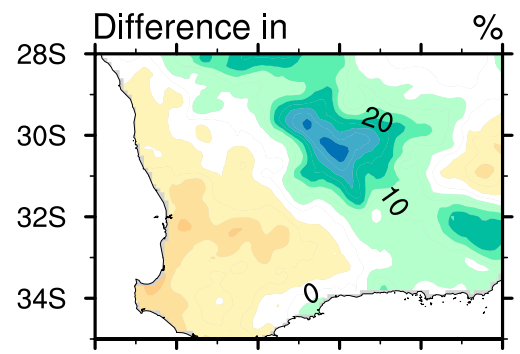

114E 116E 118E 120E 122E 124E

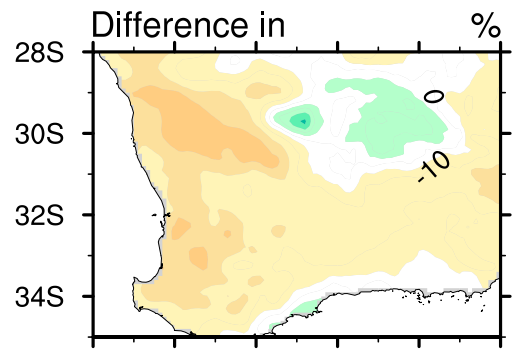

114E 116E 118E 120E 122E 124E

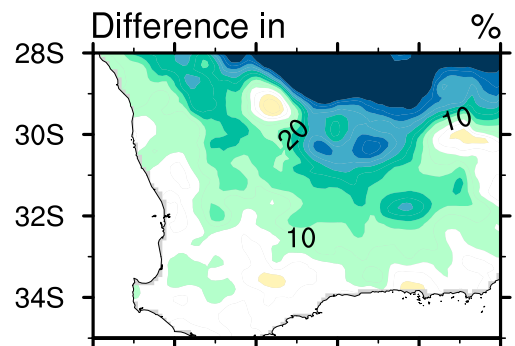

114E 116E 118E 120E 122E 124E

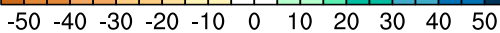

FIG. 2. (left) Mean seasonal rainfall for 1940-2010 and changes over southwestern Australia between two periods 1941-75 and 1976-2010 shown (middle) in millimeters per day and (right) as a percentage change.

$25 \%(>60 \mathrm{~mm})$. A large part of the reduction in coastal rainfall (up to $45 \mathrm{~mm}$ ) occurs in JJA, and the largest increase $(>35 \mathrm{~mm})$ over inland area is in DJF. Figure 5 shows the contribution of each cluster to the total rainfall change between the two consecutive periods 194074 and 1975-2010 [see Eq. (2)]. The major change in the rainfall is largely due to the changes in the frequency of different regimes, while contributions from the changes in the rainfall intensity are small. As expected, the second-order correction term is negligible and hence its effect is ignored here.

Cluster 1 is the cluster that changes the least each month; however, it contributes $>20 \%$ of reduction in the annual rainfall along the coast. The large reduction (up to $75 \%$ ) in June and July rainfall along the west coast is due to the decreasing frequency of clusters 2 and 3 , while the increase of up to $90 \%$ over the inland area in the summer months is due to the increased frequency of 


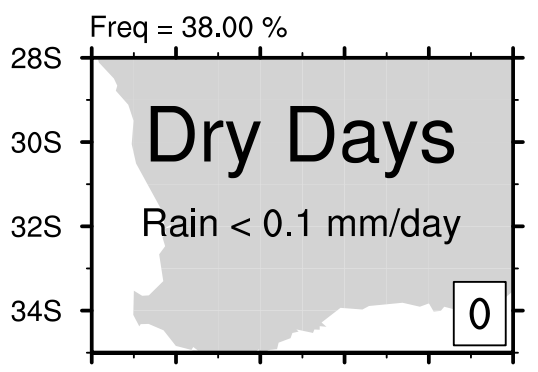

114E 116E 118E 120E 122E 124E

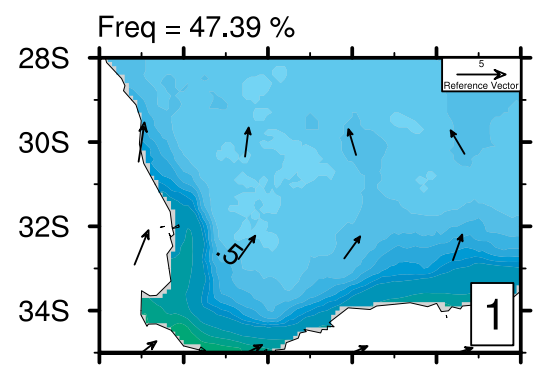

114E 116E 118E 120E 122E 124E
Freq $=8.82 \%$

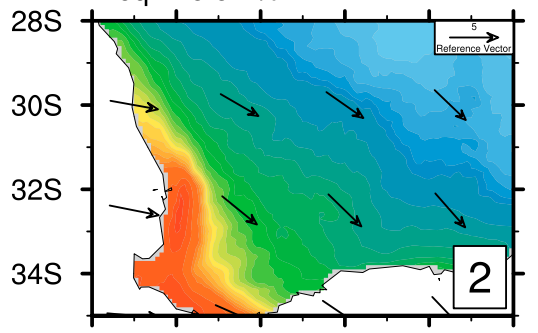

114E 116E 118E 120E 122E 124E
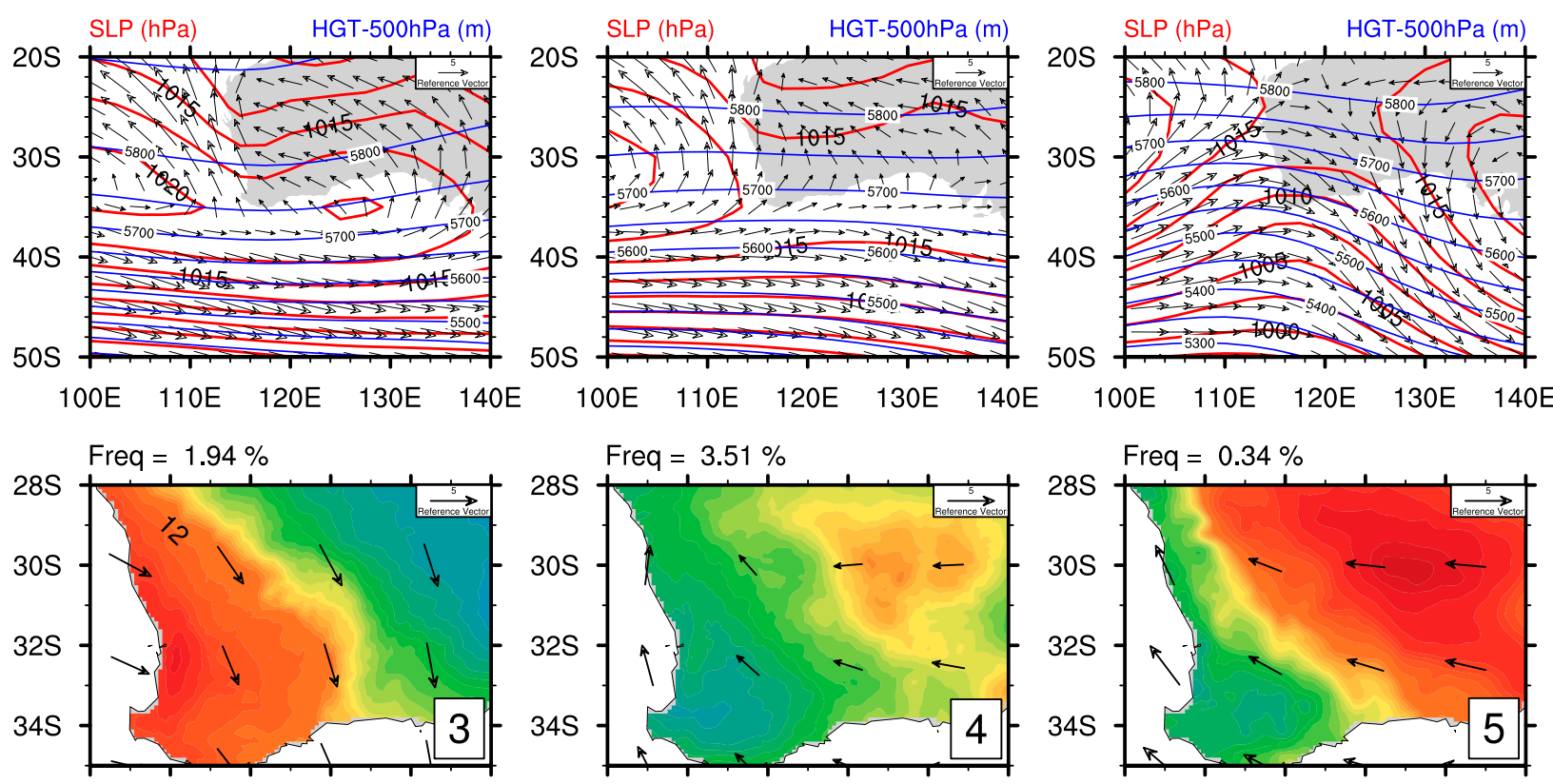

114E 116E 118E 120E 122E 124E

114E 116E 118E 120E 122E 124E

114E 116E 118E 120E 122E 124E

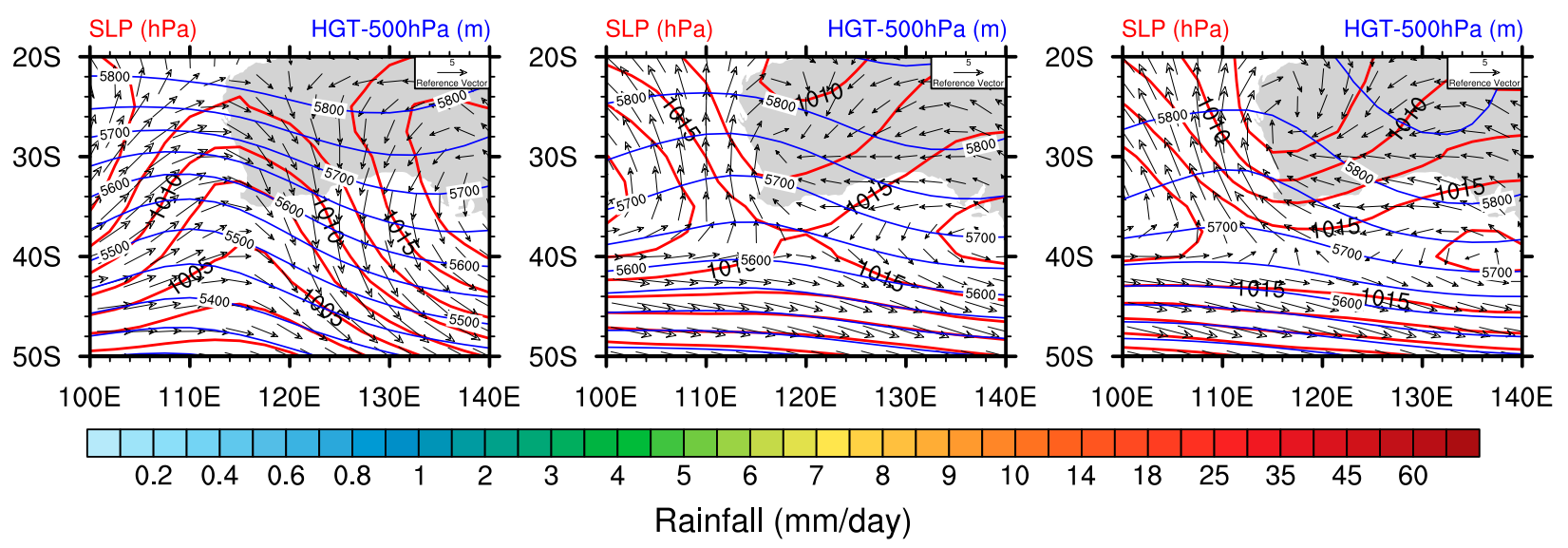

FIG. 3. Five rainfall clusters obtained from K-means clustering of the AWAP data for the period 1940-2010 are shown along with the corresponding MSLP (red contours), 500-hPa geopotential height (blue contours), and wind vectors from the NCEP reanalysis data for the period 1948-2010. The frequency of occurrences of clusters is shown at the top-left corner of each rainfall panel. These regimes are named as follows: $0=$ dry days, $1=$ light rain, $2=$ weak westerly front, $3=$ strong westerly front, $4=$ weak easterly trough, and $5=$ strong easterly trough. 

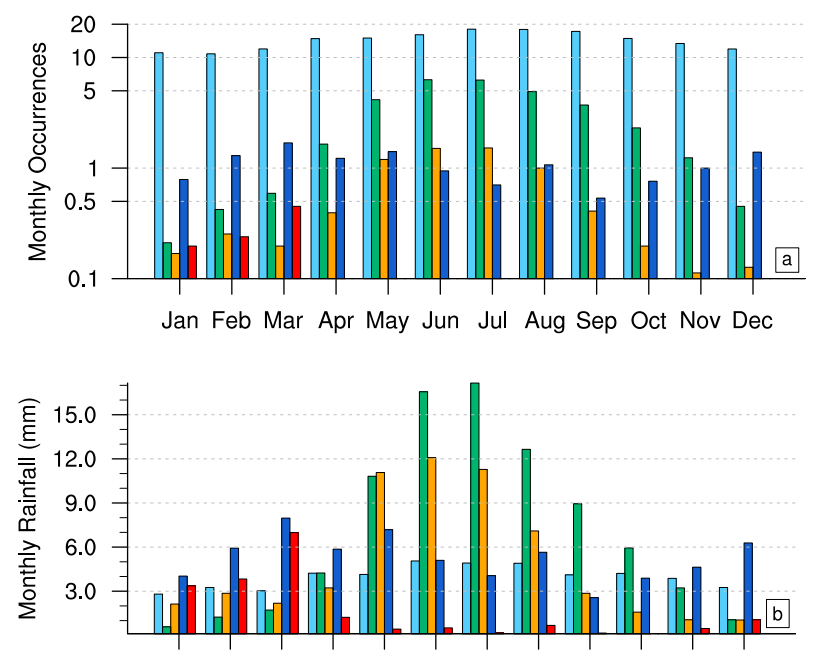

Jan Feb Mar Apr May Jun Jul Aug Sep Oct Nov Dec

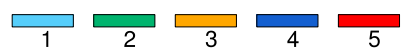

FIG. 4. (a) Mean monthly occurrences of the rainfall clusters. (b) Mean monthly accumulation of rainfall associated with the clusters.

clusters 4 and 5. The rainfall reduction in May and October in clusters 2 and 3 is more or less compensated by an increase in the frequency of cluster 4 . The frequency of cluster 4 has also increased in the winter months of July and August, which may have increased the inland rainfall at the expense of the coastal rainfall in the winter.

Figure 6 shows the annual occurrences of each cluster with the vertical lines showing breakpoints in the time series defined by the rapid changes in the means of the distributions. The red (solid) line marks the location of the most abrupt change in the mean and the green (dashed) line indicates the second strongest change. Cluster 2 has a breakpoint in the late 1970s, whereas cluster 3 has a breakpoint in the late 1960s. The frequency of both clusters has fallen after the breakpoint year. However, cluster 2 recovered from the decline in the late 1980s while the occurrences of cluster 3 remained low and fell further after the year 2000 . Thus, the reduction in the frequencies of clusters 2 and 3 explains the abrupt decrease in the winter rainfall in the 1970s. Note that the breakpoint in the occurrences of cluster 3 after 2000 is the weaker of the two. A large reduction in the light rain days during the 1990s suggests that the reduction in rainfall over last two decades is largely due to the reduction in light rain days associated with westerlies and it may include very weak fronts. A reduction (increase) of approximately 15 light rain (dry) days per annum has occurred since 1990, implying the frequency of dry days has increased at the expense of light rain days.
The breakpoints of clusters 4 and 5 more or less coincide with the breakpoints found in other clusters. In particular, there is an increase in the occurrence of cluster 4 around 1975 and a reduction after 2000; there is also a considerable $(>50 \%)$ increase in cluster 5 in the early 1990s. Thus, the increment in summer rainfall over the inland area is due to the increased frequency of rainy days associated with easterly troughs.

\section{d. Effect of SAM and ENSO on the rainfall}

To assess the effect of the SOI and SAM on the rainfall clusters, the monthly rainfall from each cluster is plotted for each combination of the three phases of ENSO and two phases of SAM. A month is categorized as neutral when the SOI lies between \pm 8 , El Niño when the SOI is less than -8 , and La Niña when the SOI exceeds 8 . For the brevity, only 4 monthsnamely, June, July, December, and February-are shown in Figs. 7 and 8. The effect of the ENSO and SAM combination is dramatically different in some adjacent months.

In June (Fig. 7), a positive phase of SAM coupled with a neutral ENSO phase is associated with reduced rainfall along the coast from clusters 2 and 3 . The rainfall from cluster 3 is approximately $5 \mathrm{~mm}$ per month when the SAM is positive but $16 \mathrm{~mm}$ per month when it is negative. Similarly, the rainfall from cluster 2 changes from 22 to $17 \mathrm{~mm}$ per month when SAM shifts from a negative to a positive phase. In a La Niña phase however, rainfall from the light rain cluster and the westerly fronts clusters (clusters 1 and 2) increases to more than double that in the positive SAM phase. In contrast, the coastal rainfall in July for a positive phase of SAM is approximately $20 \%$ lower than in a negative phase of SAM, irrespective of the phase of ENSO. Overall, a positive phase of SAM is associated with the reduction of the coastal rainfall in all the ENSO phases. El Niño is the least favorable condition for coastal rainfall when SAM is negative, although, when SAM is positive, neutral ENSO and El Niño phases are both associated with lower coastal rainfall, thus increasing the frequency of drier periods over the region.

In December (Fig. 8), a positive phase of SAM is associated with an increase in the rainfall from cluster 4 by 2-6 times in all the phases of ENSO. Except during an El Niño phase, the positive phase of SAM also tends to increase the light rainfall from cluster 1 . Similarly, February rainfall from cluster 4 increases in positive phases of SAM. During an El Niño, however, a negative SAM is accompanied by increases in the coastal rainfall from the strong westerly fronts (cluster 3). Thus, the effect of ENSO phases on the SWA rainfall is highly dependent on the phase of SAM. 
a) Change due to Intensity ( $\mathbf{N i} \cdot \Delta \mathrm{Pi})$

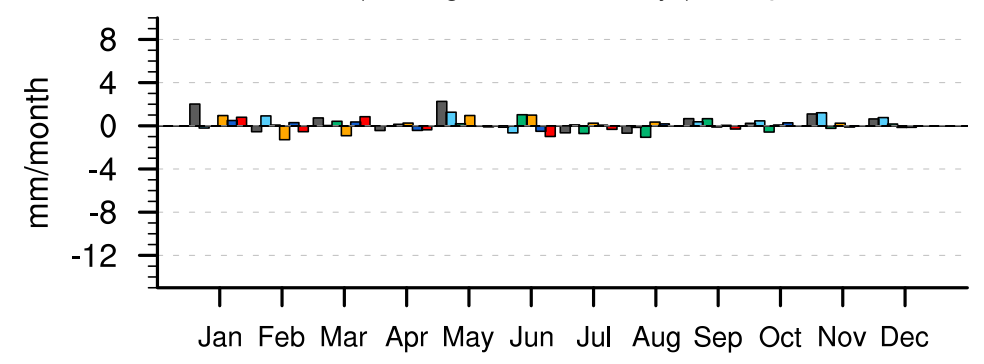

b) Change due to Frequency $(\mathbf{P i} \cdot \Delta \mathbf{N i})$

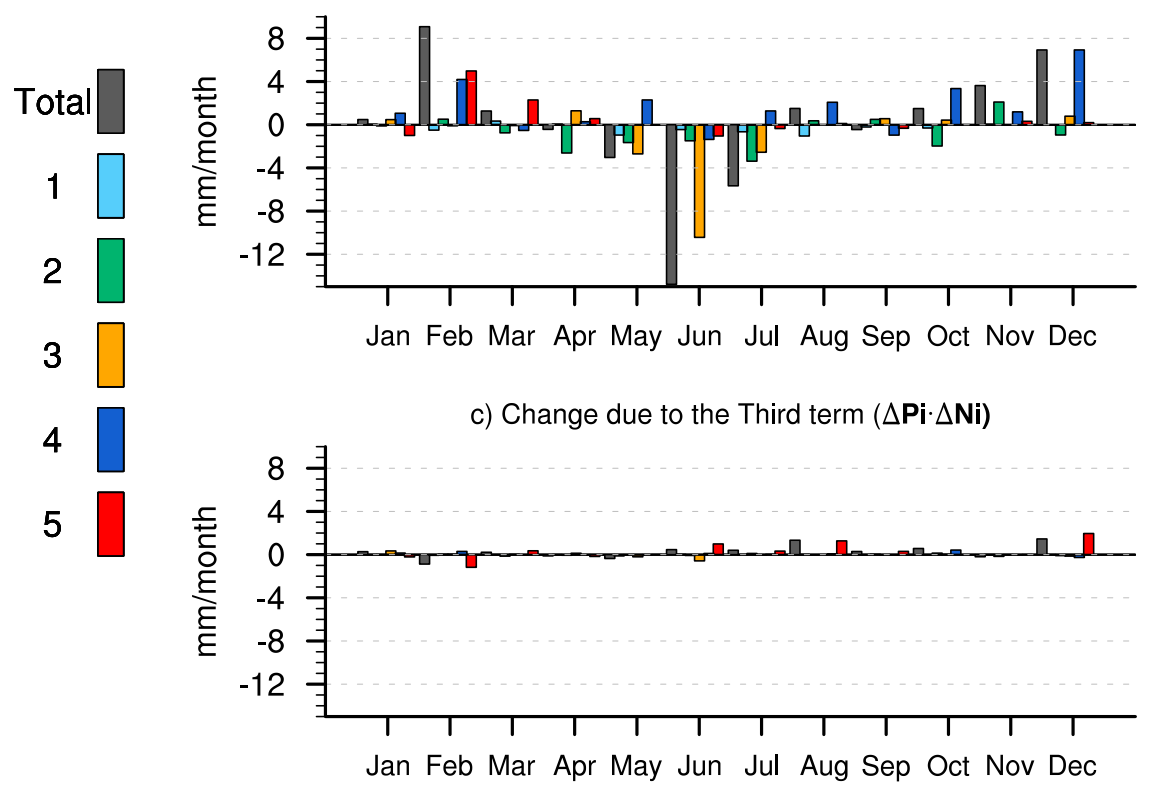

d) Total Change $(\Delta \mathbf{R})$

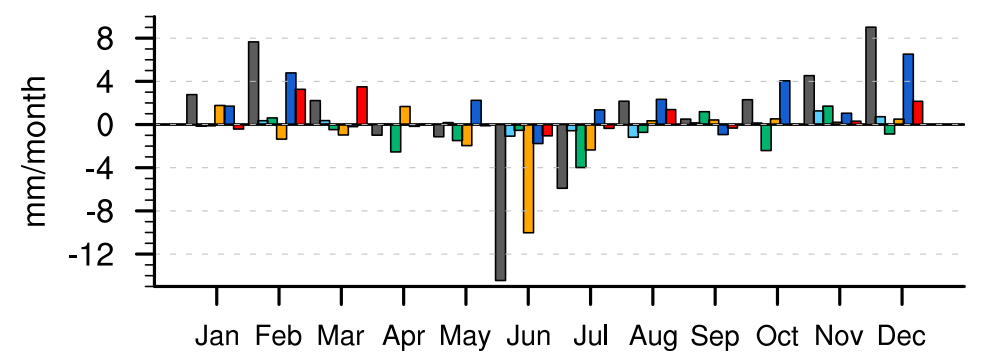

FIG. 5. Decomposition of monthly precipitation changes between the two periods into frequency and intensity for each cluster according to Eq. (2). The change in precipitation due to (a) the change in intensity of the daily rainfall, (b) the change in frequency of rainy days, and (c) the change due to the third term of Eq. (2). (d) The total precipitation change between the two periods.

Figure 9 shows monthly area-averaged rainfall for June, July, December, and February for the six combinations of ENSO and SAM phases. Note that before 1975 the combination of neutral ENSO and negative SAM (NENS) in June arose 13 times, whereas it occurred only 4 times in June during 1975-2010. On the other hand, the combination of neutral ESNO with positive SAM (NEPS) in June increased from 4 times prior to 1975 to 15 time following 1975. The number of El Niño events in June also increased significantly from 4 to 11. Similarly, in July, months with NENS fell from 17 to 9 , whereas months with NEPS rose from 5 to 10 . Thus, 

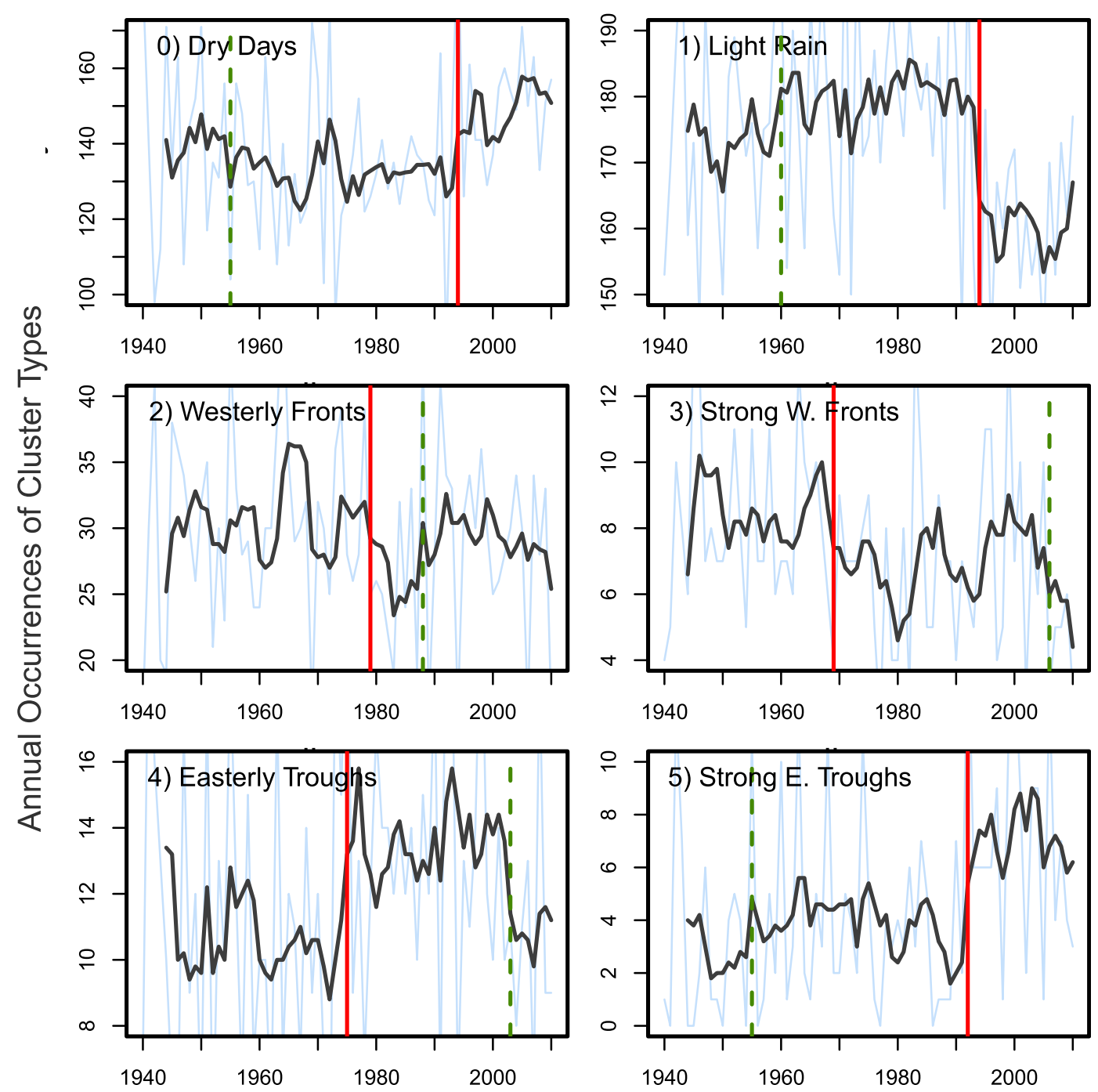

FIG. 6. Time series of the annual occurrences of each cluster type (light blue lines) and the 5-yr running average (black lines). The vertical lines show breakpoints indicating abrupt changes in the mean occurrences. The stronger breakpoint is shown as a solid red line, and a weaker breakpoint is shown as a dotted green line.

since the mid-1970s the most favorable conditions for coastal rainfall in June-July have changed to the least favorable. Over the inland region, increasing December and February rainfall since 1975 is associated with a reduction in the frequency of NENS months and an increase in the frequency of NEPS months. An increased frequency in La Niñas and positive phase of SAM may also have increased the rainfall over this region in summer.

\section{Discussion}

The above results show that clustering on rainfall patterns is a useful technique for studying rainfall changes as a function of synoptic conditions and also in linking these changes to large-scale climate modes such as ENSO and SAM. The study shows that the major decline in the winter rainfall over coastal SWA is due to the overall reduction in the frequency of westerly fronts, particularly strong fronts. Moreover, the increase in rainfall over the inland area of SWA is the result of an increased frequency of easterly troughs in December and February. Both the reduction in winter and the increase in summer rainfall are shown to depend on the phases of both SAM and ENSO; the positive phase of SAM is associated with reduced (enhanced) winter (summer) rainfall in all the three ENSO phases. Also the neutral phase of ENSO in combination with the positive phase of SAM occurred more often in the post-1970s than the earlier period and such a combination is 
a) June
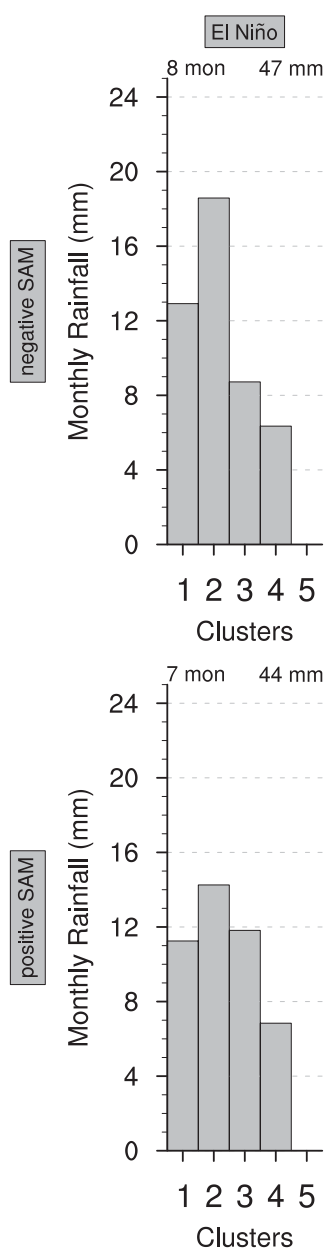
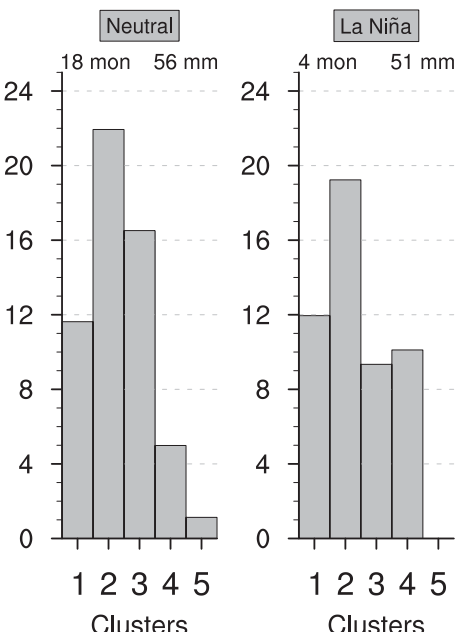

12345

Clusters
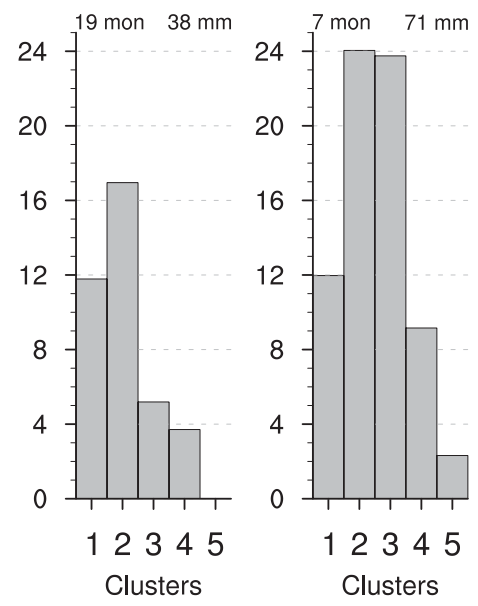

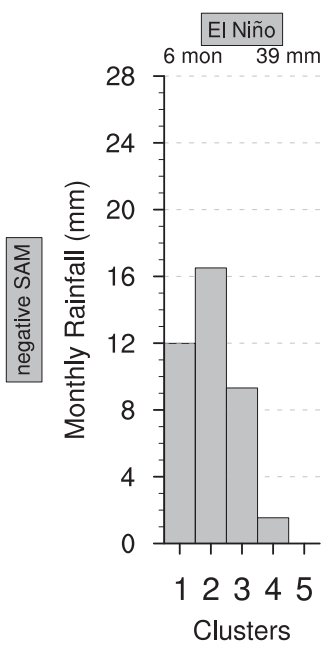

b) July
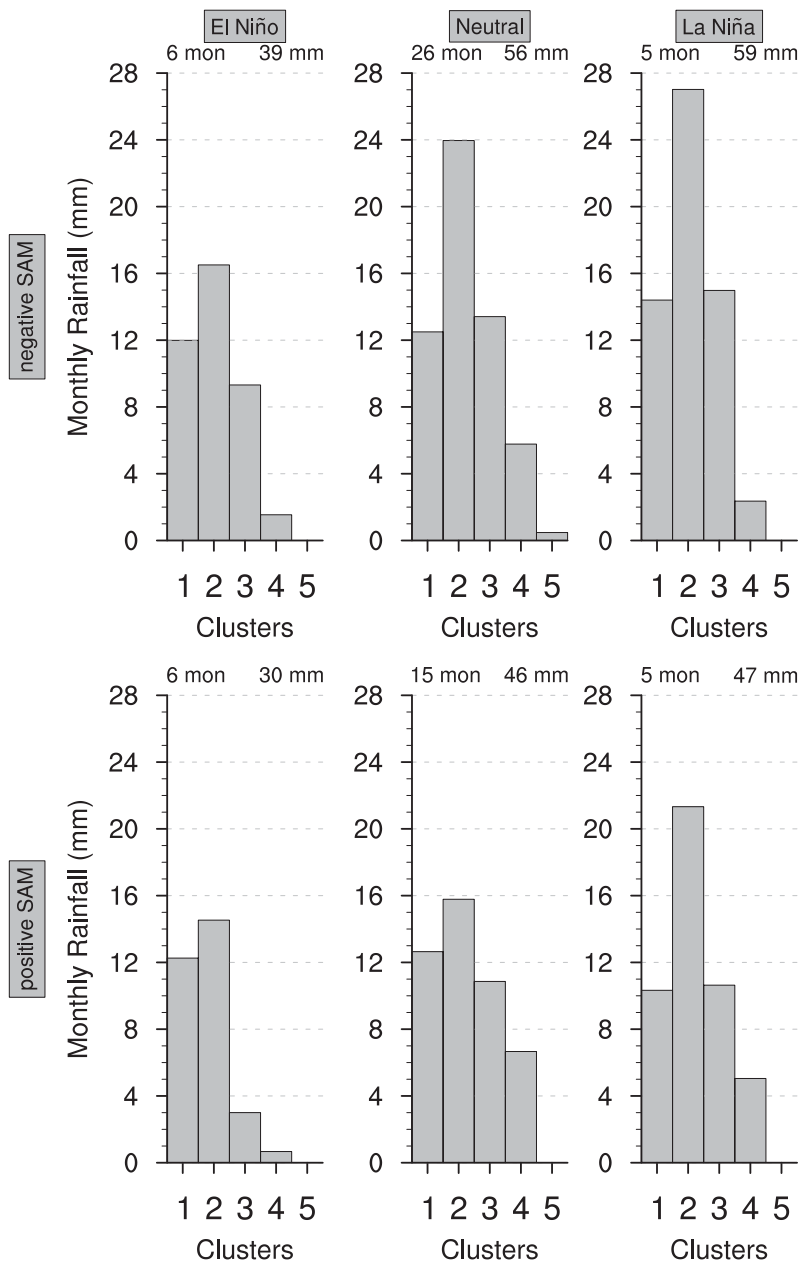

FIG. 7. The combined effect of the monthly phases of ENSO and SAM on monthly rainfall associated with each cluster during 19482010 for (a) June and (b) July. The number of months in each category and the total mean area monthly rainfall are listed at the top of each panel.

associated with reduced rainfall from westerly fronts and increased rainfall from easterly troughs.

The K-means clustering method bins rainfall according to the magnitude and geographic distribution, giving separate classes for the coastal and inland rainfall and separate classes for heavy events and light or moderate events. Clustering on rainfall patterns is an important aspect of the study presented here as it allows for a direct and consistent estimation of the change (or trend) in the rainfall associated with any cluster. Experience shows that clustering on MSLP (Hope et al. 2006; Alexander et al. 2010) or any other smooth variable does not clearly differentiate heavy rainfall conditions from the more frequent light rain conditions. Moreover, dry days dominate all such clusters. Changes in comparatively less frequent heavy events can cause significant changes in the mean rainfall as is evident in case of clusters 3 and 5 in this study.

The results are qualitatively consistent with the earlier studies (Hope et al. 2006; Alexander et al. 2010) over coastal SWA showing that the decreasing frequency of fronts is mainly responsible for the declining rainfall. Moreover, the results reported here support the conclusion that a large fraction of the decline (more than $50 \%$ ) in JJA is due to the fewer occurrences of strong fronts. It appears that the conditions after the 1970s have reduced the number of fronts in general and prevented the strengthening of the frontal systems. The decrease in the number of strong fronts has contributed more to the decline in rainfall than the decrease in weak fronts. This result was also noted by Nicholls et al. (1997). The current study shows that the reduction in rainfall in the 


\section{a) December}
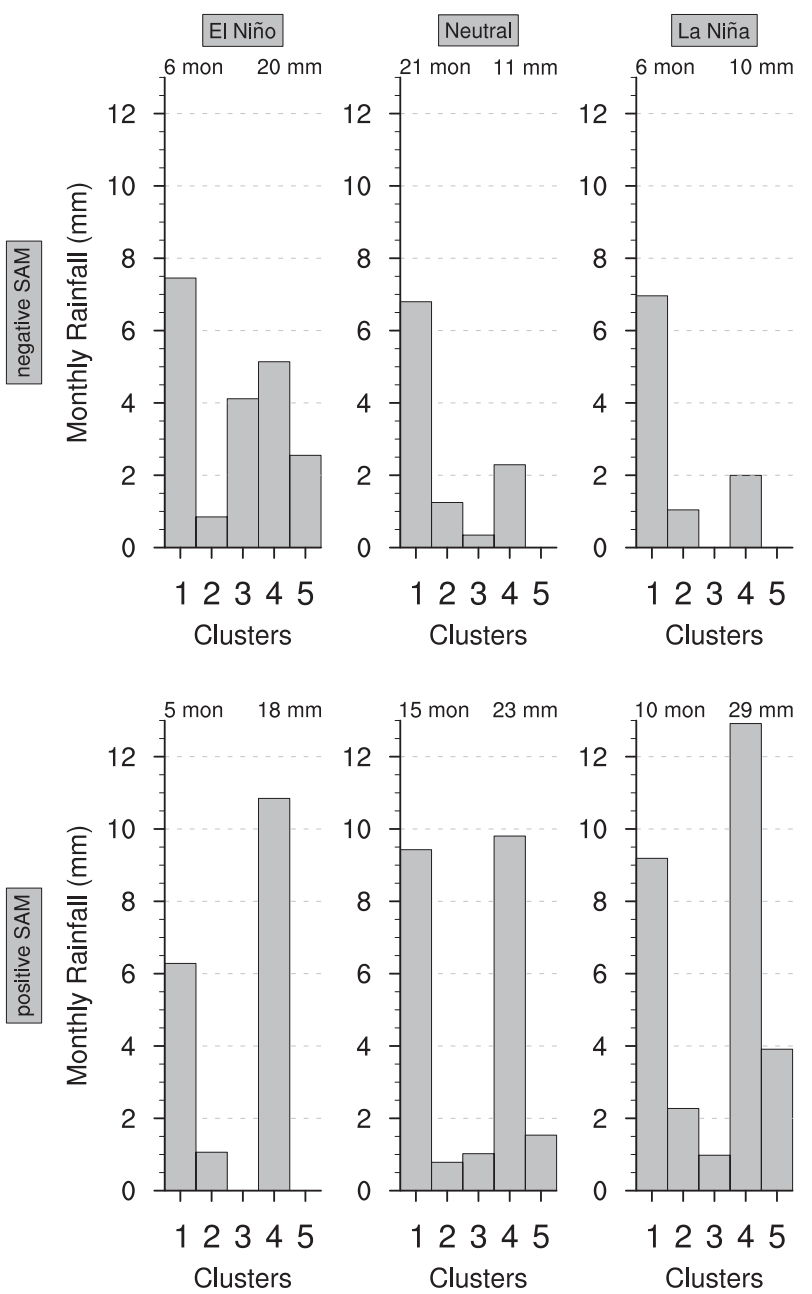
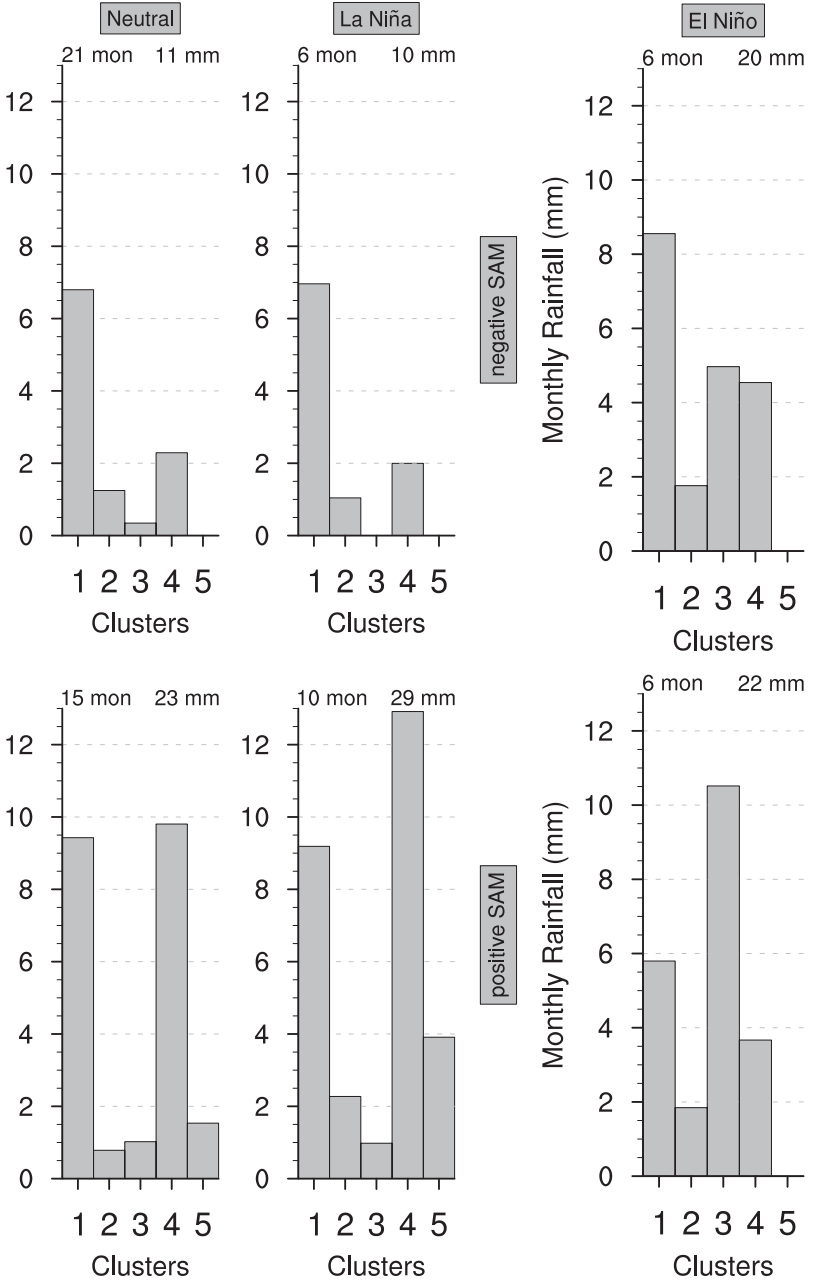

b) February
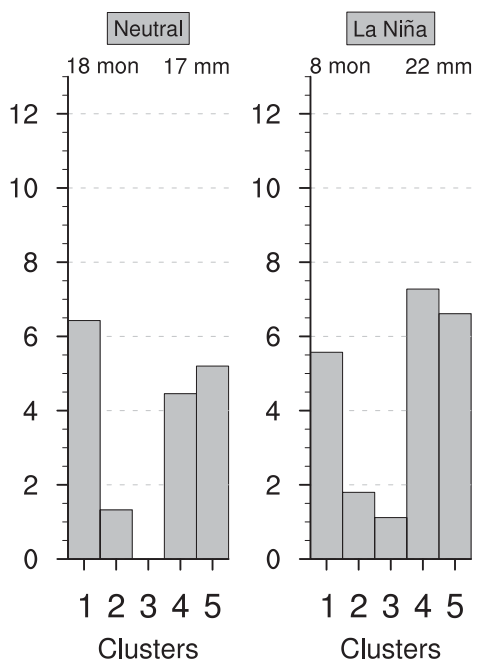

FIG. 8. As in Fig. 7, but for (a) December and (b) February.
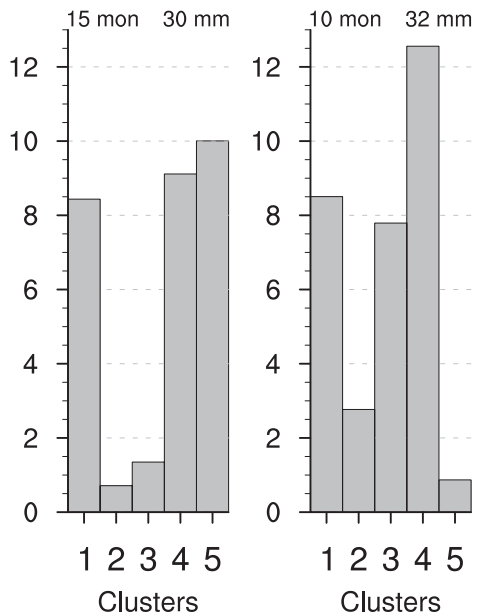

1970s was mainly due to fewer fronts, whereas an increase in the number of dry days, associated with the persistent high, is responsible for the recent decline in the 1990s (see Fig. 6). A reduction in the frequency of fronts did not increase the number of dry days in the 1970s and the change in light rain days was also small.

The increased rainfall over the inland area is due to an increase in the frequency of raining easterly troughs, although, without any objective method to identify such troughs, it is difficult to know whether the frequency of all troughs (both wet and dry) changed during this period. Recently, a front detection method used in Berry et al. (2011b) showed a higher frequency of fronts in DJF as compared to JJA and an increasing trend in annual frequency of fronts over SWA (Berry et al. 2011a). Using the same method Catto et al. (2012a) showed that a large fraction of the DJF rainfall is connected to warm fronts, whereas JJA rainfall is mainly connected to cold fronts. It is likely that many of the fronts over Western Australia detected by Berry et al. (2011b) are associated with the easterly troughs and the increase in the number of summertime easterly troughs is reflected in the annual increase of the number of fronts. As the frequency of frontal clusters (i.e., clusters 2 and 3) fell in the 1970s and the data used by Berry et al. (2011a) only start in 1989, this reduction is not evident in their study. A more focused study using objective analysis is required to determine the seasonal trends in fronts, troughs, and cutoff lows in this area.

Hendon et al. (2007) concluded that the effect of SAM is comparable to the effect of the ESNO on coastal SWA rainfall in winter. Moreover, the current results suggest that a positive phase of SAM dramatically affects the development of fronts in winter and also strengthens easterly troughs in summer, producing up to 5 times the rainfall in some situations (Fig. 8). The effect of SAM on 

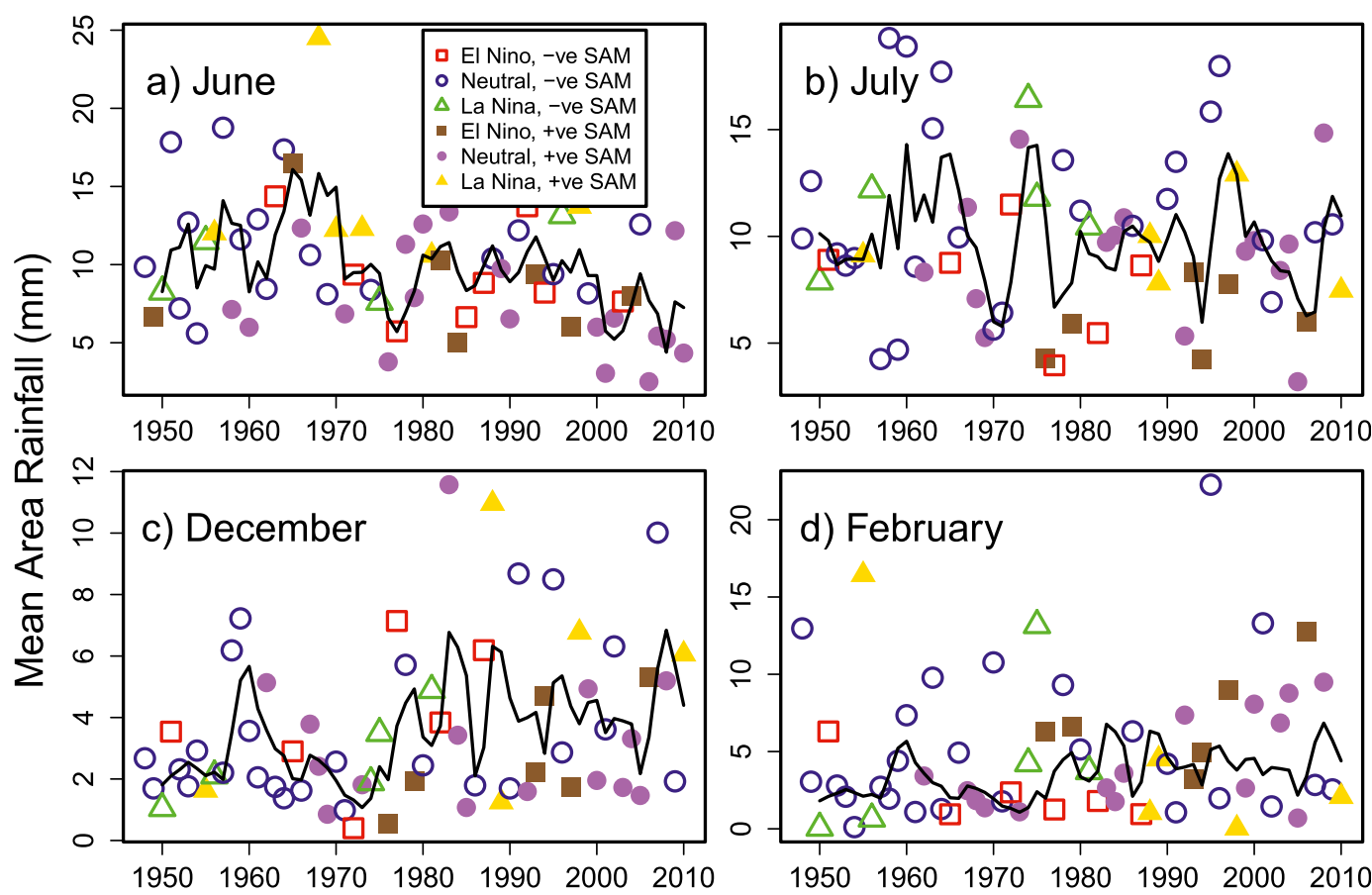

FIG. 9. A 5-point running average of the monthly rainfall time series for (a) June, (b) July, (c) December, and (d) February. Monthly rainfall accumulations are plotted with the colored symbols corresponding to SAM-ENSO combinations as shown in Fig. 7 and 8.

rainfall is most pronounced during the neutral phase of ENSO, which occurs more often than the El Niño and La Niña phases combined. For example, during 19482010 only 22 Julys were classified as El Niño or La Niña but 41 Julys were neutral. Consequently, the phase of SAM has much greater influence during these neutral months, resulting in a long-term trend in SWA rainfall. In addition, the change in ENSO from El Niño to neutral condition significantly affects the monthly rainfall whereas the change from neutral to La Niña only slightly affects it. In contrast to the results of Meneghini et al. (2007) and Risbey et al. (2009), the monthly SAM index is shown to strongly influence SWA rainfall. This difference could be due to the inability of correlation analysis to capture the exact strength of the nonlinear and interdependent relationship between rainfall and the SAM index.

A reduction in the strength of the southern hemispheric subtropical jet stream and an associated poleward displacement of the storm tracks is linked to the declining coastal rainfall in winter (Frederiksen and Frederiksen 2007; Frederiksen et al. 2011) and enhancing the inland rainfall in summer. During the positive phase of SAM, the poleward shift in the subtropical jet increases the precipitation at the poleward flank of the jet and decreases it over the subtropical latitudes in winter (Hendon et al. 2014). In summer, a southward shift in the westerlies associated with positive phase of SAM allows easterly troughs to penetrate more frequently into higher latitudes.

The recent phase 5 of the Climate Model Intercomparison Project (CMIP5) simulations for this century, using the representative concentration pathway 4.5 (RCP4.5) greenhouse gas emission scenario, show a very weak negative trend in the SAM index, in contrast a strong positive trend is projected when the RCP8.5 scenario is used (Zheng et al. 2013). Polade et al. (2014) also showed 10-20 fewer rainy days and at least a $10 \%$ reduction in the total annual rainfall over SWA in CMIP5 models for the RCP8.5 emission scenario, compared to the historical simulations. In the light of these results, the current study should be extended using CMIP5 simulations of SAM, ENSO, and rainfall over SWA.

Acknowledgments. This work received funding from Cooperative Research Centre for Water Sensitive Cities. NCEP-NCAR reanalysis data were obtained from NOAA portal. AWAP data were obtained from Bureau of Meteorology with the help of Ailie Gallant. The authors thank Michael J. Murphy and Jackson Tan for valuable suggestions they offered during the scientific writing workshop conducted by ARC Centre of Excellence for Climate System Science. The NCAR Command 
Language (NCL; http://dx.doi.org/10.5065/D6WD3XH5), R Programming language (http://www.R-project.org), and Climate Data Operators (CDO) were used for data analysis and plotting purposes. We are grateful to James Risbey and an anonymous reviewer for their insightful comments.

\section{REFERENCES}

Alexander, L. V., P. Uotila, N. Nicholls, and A. Lynch, 2010: A new daily pressure dataset for Australia and its application to the assessment of changes in synoptic patterns during the last century. J. Climate, 23, 1111-1126, doi:10.1175/ 2009JCLI2972.1.

Allan, R. J., and M. R. Haylock, 1993: Circulation features associated with the winter rainfall decrease in southwestern Australia J. Climate, 6, 1356-1367, doi:10.1175/1520-0442(1993)006<1356: CFAWTW $>2.0 . \mathrm{CO} ; 2$.

Anderberg, M. R., 1973: Cluster Analysis for Applications. Academic Press, 359 pp.

Ansell, T. J., C. J. C. Reason, I. N. Smith, and K. Keay, 2000: Evidence for decadal variability in southern Australian rainfall and relationships with regional pressure and sea surface temperature. Int. J. Climatol., 20, 1113-1129, doi:10.1002/ 1097-0088(200008)20:10<1113::AID-JOC531>3.0.CO;2-N.

Bates, B. C., P. Hope, B. Ryan, I. Smith, and S. Charles, 2008: Key findings from the Indian Ocean Climate Initiative and their impact on policy development in Australia. Climatic Change, 89, 339-354, doi:10.1007/s10584-007-9390-9.

Berry, G., C. Jakob, and M. Reeder, 2011a: Recent global trends in atmospheric fronts. Geophys. Res. Lett., 38, L21812, doi:10.1029/ 2011GL049481.

— M. J. Reeder, and C. Jakob, 2011b: A global climatology of atmospheric fronts. Geophys. Res. Lett., 38, L04809, doi:10.1029/2010GL046451.

Catto, J. L., C. Jakob, G. Berry, and N. Nicholls, 2012a: Relating global precipitation to atmospheric fronts. Geophys. Res. Lett., 39, L10805, doi:10.1029/2012GL051736.

,-- , and N. Nicholls, 2012b: The influence of changes in synoptic regimes on north Australian wet season rainfall trends. J. Geophys. Res., 117, D10102, doi:10.1029/ 2012JD017472

Chowdhury, R. K., and S. Beecham, 2010: Australian rainfall trends and their relation to the Southern Oscillation index. Hydrol. Processes, 24, 504-514, doi:10.1002/hyp.7504.

Feng, J., J. Li, and Y. Li, 2010: Is there a relationship between the SAM and southwest Western Australian winter rainfall? J. Climate, 23, 6082-6089, doi:10.1175/2010JCLI3667.1.

Fierro, A. O., and L. M. Leslie, 2013: Links between central west Western Australian rainfall variability and large-scale climate drivers. J. Climate, 26, 2222-2246, doi:10.1175/ JCLI-D-12-00129.1.

Frederiksen, J. S., and C. S. Frederiksen, 2007: Interdecadal changes in Southern Hemisphere winter storm track modes. Tellus, 59A, 599-617, doi:10.1111/j.1600-0870.2007.00264.x.

, — - S. L. Osbrough, and J. M. Sisson, 2011: Changes in Southern Hemisphere rainfall, circulation and weather systems. Proc. 19th Int. Congress on Modelling and Simulation, Perth, WA, Australia, Modelling and Simulation Society of Australia and New Zealand, 2712-2718. [Available online at http://www.mssanz.org.au/modsim2011/index.htm.]
Gallant, A. J. E., M. J. Reeder, J. S. Risbey, and K. J. Hennessy, 2013: The characteristics of seasonal-scale droughts in Australia, 1911-2009. Int. J. Climatol., 33, 1658-1672, doi:10.1002/ joc. 3540

Gong, D., and S. Wang, 1999: Definition of Antarctic oscillation index. Geophys. Res. Lett., 26, 459-462, doi:10.1029/ 1999GL900003.

Hendon, H. H., D. W. J. Thompson, and M. C. Wheeler, 2007: Australian rainfall and surface temperature variations associated with the Southern Hemisphere annular mode. J. Climate, 20, 2452-2467, doi:10.1175/JCLI4134.1.

, E.-P. Lim, and H. Nguyen, 2014: Seasonal variations of subtropical precipitation associated with the southern annular mode. J. Climate, 27, 3446-3460, doi: 10.1175/JCLI-D-1300550.1.

Hope, P., W. Drosdowsky, and N. Nicholls, 2006: Shifts in the synoptic systems influencing southwest Western Australia. Climate Dyn., 26, 751-764, doi:10.1007/s00382-006-0115-y.

_- and Coauthors, 2014: A comparison of automated methods of front recognition for climate studies: A case study in southwest Western Australia. Mon. Wea. Rev., 142,343-363, doi:10.1175/ MWR-D-12-00252.1.

IOCI, 2002: Climate variability and change in south west Western Australia. IOCI Rep., 34 pp.

Jones, D., W. Wang, and R. Fawcett, 2009: High-quality spatial climate data-sets for Australia. Aust. Meteor. Oceanogr. J., 58, 233-248.

Kalnay, E., and Coauthors, 1996: The NCEP/NCAR 40-Year Reanalysis Project. Bull. Amer. Meteor. Soc., 77, 437-471, doi:10.1175/1520-0477(1996)077<0437:TNYRP>2.0.CO;2.

Li, F., L. E. Chambers, and N. Nicholls, 2005: Relationships between rainfall in the southwest of Western Australia and nearglobal patterns of sea-surface temperature and mean sea-level pressure variability. Aust. Meteor. Mag., 54, 23-33.

McBride, J. L., and N. Nicholls, 1983: Seasonal relationships between Australian rainfall and the Southern Oscillation. Mon. Wea. Rev., 111, 1998-2004, doi:10.1175/1520-0493(1983)111<1998: SRBARA $>2.0 . \mathrm{CO} ; 2$.

Meneghini, B., I. Simmonds, and I. N. Smith, 2007: Association between Australian rainfall and the southern annular mode. Int. J. Climatol., 27, 109-121, doi:10.1002/joc.1370.

Nicholls, N., 2006: Detecting and attributing Australian climate change: A review. Aust. Meteor. Mag., 55, 199-211.

, 2010: Local and remote causes of the southern Australian autumn-winter rainfall decline, 1958-2007. Climate Dyn., 34, 835-845, doi:10.1007/s00382-009-0527-6.

— L. Chambers, M. Haylock, C. S. Frederiksen, D. Jones, and W. Drosdowsky, 1997: Climate variability and predictability for south-west Western Australia. IOCI Phase 1 Rep., 52 pp.

Pezza, A. B., T. Durrant, I. Simmonds, and I. Smith, 2008: Southern hemisphere synoptic behavior in extreme phases of SAM, ENSO, sea ice extent, and southern Australia rainfall. J. Climate, 21, 5566-5584, doi:10.1175/2008JCLI2128.1.

Pitman, A. J., G. T. Narisma, R. A. Pielke Sr., and N. J. Holbrook, 2004: Impact of land cover change on the climate of southwest Western Australia. J. Geophys. Res., 109, D18109, doi:10.1029/ 2003JD004347.

Polade, S. D., D. W. Pierce, D. R. Cayan, A. Gershunov, and M. D. Dettinger, 2014: The key role of dry days in changing regional climate and precipitation regimes. Sci. Rep., 4, 4364, doi:10.1038/srep04364.

Pook, M. J., J. S. Risbey, and P. C. McIntosh, 2012: The synoptic climatology of cool-season rainfall in the central wheatbelt of 
Western Australia. Mon. Wea. Rev., 140, 28-43, doi:10.1175/ MWR-D-11-00048.1.

$\ldots, \ldots$, and $\_$, 2013: A comparative synoptic climatology of cool-season rainfall in major grain-growing regions of southern Australia. Theor. Appl. Climatol, doi:10.1007/ s00704-013-1021-y.

Pope, M., C. Jakob, and M. J. Reeder, 2009: Regimes of the north Australian wet season. J. Climate, 22, 6699-6715, doi:10.1175/ 2009JCLI3057.1.

Qi, L., L. M. Leslie, and S. X. Zhao, 1999: Cut-off low pressure systems over southern Australia: Climatology and case study. Int. J. Climatol., 19, 1633-1649, doi:10.1002/ (SICI)1097-0088(199912)19:15<1633::AID-JOC445>3.0.CO;2-0.

Raupach, M. R., P. Briggs, V. Haverd, E. King, M. Paget, and C. Trudinger, 2008: Australian Water Availability Project: CSIRO Marine and Atmospheric Research component: Final report for phase 3. CAWCR Tech. Rep. 013, 67 pp. [Available online at http://www.csiro.au/awap/doc/CTR_013_ online_FINAL.pdf.]

Risbey, J. S., M. J. Pook, P. C. McIntosh, M. C. Wheeler, and H. H. Hendon, 2009: On the remote drivers of rainfall variability in
Australia. Mon. Wea. Rev., 137, 3233-3253, doi:10.1175/ 2009MWR2861.1.

,$- \ldots$, and — 2013: Spatial trends in synoptic rainfall in southern Australia. Geophys. Res. Lett., 40, 3781-3785, doi:10.1002/grl.50739.

Smith, I. N., P. C. McIntosh, T. J. Ansell, C. J. C. Reason, and K. McInnes, 2000: Southwest Western Australian winter rainfall and its association with Indian Ocean climate variability. Int. J. Climatol., 20, 1913-1930, doi:10.1002/ 1097-0088(200012)20:15<1913::AID-JOC594>3.0.CO;2-J.

Stone, R. C., 1989: Weather types at Brisbane, Queensland: An example of the use of principal components and cluster analysis. Int. J. Climatol., 9, 3-32, doi:10.1002/joc.3370090103.

Suppiah, R., and K. J. Hennessy, 1998: Trends in total rainfall, heavy rain events and number of dry days in Australia, 1910-1990. Int. J. Climatol., 18, 1141-1164, doi:10.1002/ (SICI)1097-0088(199808)18:10<1141::AID-JOC286>3.0.CO;2-P.

Zheng, F., J. Li, R. T. Clark, and H. C. Nnamchi, 2013: Simulation and projection of the Southern Hemisphere annular mode in CMIP5 models. J. Climate, 26, 9860-9879, doi:10.1175/ JCLI-D-13-00204.1. 